\title{
Evoluciones recientes de la contratación pública en México*
}

\author{
Guillermo Cambero Quezada* \\ Recibido: 18 de marzo de 2015 • Revisado: 3 de abril de 2015
}

Aprobado: 26 de abril de 2015

\section{Resumen}

El presente artículo pretende demostrar la incipiente existencia de un sistema de exorbitancia de derecho público y la dualidad jurisdiccional del sistema jurídico mexicano. Por otra parte, se analiza el marco general de la contratación pública en México; esto es, desde las etapas precontractual y contractual, intentando desarrollar los ítems más relevantes de las mencionadas etapas.

El contenido del documento es producto de una investigación explicativa porque estuvo dirigida a responder las causas de la incipiente existencia de un sistema de exorbitancia de derecho público en el marco de la contratación estatal.

Palabras clave: contratos administrativos, adquisiciones, compras públicas, gobierno federal, medios electrónicos.

"El presente artículo es producto del proyecto de investigación de la tesis doctoral del autor, quien cursó estudios doctorales en la Universidad de Nantes (Francia).

" Doctor en Derecho por la Universidad de Nantes (Francia). Profesor de Derecho Administrativo de la Universidad de Guadalajara - México. Correo electrónico: gcambero@camberoabogados.com 


\title{
RECENT DEVELOPMENTS OF GOVERNMENT PROCUREMENT IN MeXico
}

\begin{abstract}
:
This article aims to demonstrate the existence of a nascent system of public law and exorbitant jurisdictional duality of the Mexican legal system. Moreover, the general framework for public procurement in Mexico is analyzed; that is, from the pre contractual and contractual stages, trying to develop the most important stages of the above items.

The content of the document is the product of an explanatory research that was aimed at answering the causes of incipient existence of a system of exorbitant public law under government procurement.
\end{abstract}

Keywords: Administrative contracts, procurement, federal government, electronic media.

\section{Evoluções recentes da contratação pública no México}

\section{Resumo}

O presente artigo tem como objetivo demonstrar a incipiente existência de um sistema de exorbitância de direito público e a dualidade jurisdicional do sistema jurídico mexicano. Além disso, analisa-se o quadro geral para os contratos públicos no México; isto é, a partir das fases pré-contratuais e contratuais, tentando desenvolver os itens mais importantes das etapas citadas.

O conteúdo do documento é o produto de uma pesquisa explicativa, que foi dirigido para responder as causas da existência incipiente de um sistema de exorbitância de direito público no quadro da contratação estadual.

Palavras-chave: Contratos administrativos, aquisições, compras públicas, governo federal, meios eletrônicos.

\section{Introducción}

El Estado mexicano, debido a su organización política federalista, representa un bloque de estados y leyes, que visto desde la óptica de un Estado unitario, como 
lo es el caso de Colombia, puede representar un cierto grado de confusión. El Artículo 40 dispone: es voluntad del pueblo mexicano constituirse en una República representativa, democrática, laica, federal, compuesta de estados libres y soberanos en todo lo concerniente a su régimen interior; pero unidos en una federación establecida según los principios de esta ley fundamental. Por tal motivo, en el presente estudio analizaremos la contratación pública respecto a las instituciones del gobierno federal o nacional (tanto administración centralizada y la paraestatal). El Artículo 90 de la constitución mexicana establece: la Administración Pública Federal será centralizada y paraestatal conforme a la Ley Orgánica que expida el Congreso, que distribuirá los negocios del orden administrativo de la Federación que estarán a cargo de las Secretarías de Estado y definirá las bases generales de creación de las entidades paraestatales y la intervención del ejecutivo federal en su operación. Para el efecto, es importante anotar que en la práctica los Estados siguen un esquema muy similar al gobierno federal y hacen uso de la publicidad en el sistema electrónico de compras del gobierno nacional.

La práctica formal de la contratación pública en México es relativamente reciente, el marco jurídico que regula la contratación en México es la Ley de Obras Públicas y Servicios Relacionados con las Mismas y la Ley de Adquisiciones, Arrendamientos y Servicios del Sector Público, ambas del año 2000, sin embargo, como lo indica Fernández (2001): "la práctica de adjudicaciones y celebración de contratos en el sector público en México se ha convertido en un hábito que predica la corrupción” (p. 476), y ha estado influenciada por la reiterada falta de rectitud. Esto aunado, a un sistema muy endeble de derecho disciplinario. El 27 de mayo de 2015 se adicionó el Artículo 113 Constitucional: El Sistema Nacional Anticorrupción es la instancia de coordinación entre las autoridades de todos los órdenes de gobierno competentes en la prevención, detección y sanción de responsabilidades administrativas y hechos de corrupción, así como en la fiscalización y control de recursos públicos. Sin embargo, al día de hoy aún no existe la ley reglamentaria del nuevo artículo 113 Constitucional. Pese a lo anterior, el marco jurídico de contratación pública sigue evolucionando, revestido de puntos fuertes y puntos débiles, los cuales analizaremos en el presente estudio, así como su funcionamiento actual.

Definiremos y analizaremos a profundidad el marco general de los contratos públicos en México, definidos por un sistema exorbitante y construyendo un sistema de dualidad jurisdiccional (primera parte). Por otra parte, se estudiará el 
esquema general de la contratación pública en México (segunda parte), en la cual demostraremos los candados jurídicos y los esfuerzos para fortalecer el sistema de contratación pública.

\section{Aspectos generales de los contratos administrativos en México}

En México, el derecho administrativo no se entiende desde la perspectiva de una Estado unitario o central, como lo es Colombia (Abello, 2015) o Francia, ya que en México dicho derecho no se concibió desde una perspectiva de derecho exorbitante, sino que el derecho civil por mucho tiempo aportaba las soluciones. En Colombia tenemos una larga tradición jurídica en materia de contratación estatal, particularmente en el sector de infraestructura, donde tanto el Consejo de Estado como los tribunales arbitrales se han encargado de desarrollar una vasta e interesante jurisprudencia en torno a los asuntos más controversiales de los contratos de concesión, decisiones que hacen que exista cierta seguridad en los asuntos que se someten a controversia. Por lo tanto la definición de los contratos administrativos es muy reciente y han sido los tribunales federales que han intervenido para delimitar el concepto de los mismos, definiendo sus alcances jurídicos dentro del sistema jurídico mexicano, los cuales no constituyen actos administrativos aislados, sino un verdadero procedimiento jurídico que busca una licitación o adjudicación. En particular en México, el instrumento legal que regula la contratación pública, según el artículo 134 párrafo 3 de la Constitución mexicana. A diferencia de un sistema unitario, en México son los tribunales federales lo que tienen la competencia de armonizar el sistema jurídico nacional a través del juicio de amparo.

\section{a. La exorbitancia de los contratos de la administración}

Indiscutiblemente, la administración pública mexicana, a la par del proceder mediante actos unilaterales, utiliza el proceder contractual, en el cual una situación jurídica nueva es creada por el acuerdo de voluntades de los interesados. Al respecto, el derecho francés aporta mediante su jurisprudencia una solución al problema de saber si un acto constitutivo de una agencia regional de hospitalización constituye un acto unilateral o un contrato (Consejo de Estado, 1998, p. 164). En México aún no existe una clasificación normativa o jurisprudencial al respecto. 
Un ejemplo claro de dicha dualidad de proceder lo esclarece la Suprema Corte de la Justicia de la Nación (SCJN), en jurisprudencia P./J. 92/2001 en relación a los servicios públicos relacionados al agua potable: al constituir el suministro de agua potable la prestación de un servicio público por el Estado como medio para la realización de un fin, que es el interés general y que se lleva a cabo mediante la celebración de un contrato administrativo de adhesión, en el que se estipulan las obligaciones y contraprestaciones entre las partes, donde el prestador de servicios y el beneficiario adquieren derechos y obligaciones recíprocos, bajo condiciones que fija el proveedor, la relación jurídica existente entre el prestador y el usuario del servicio no corresponde a la que supone la garantía consagrada en el artículo 14 de la Constitución Política de los Estados Unidos Mexicanos, esto es, a la existente entre una autoridad y un gobernado, sino a la de coordinación voluntaria y de correspondencia entre el interés del prestador del servicio de suministro de agua y el particular, y aun cuando la prestación del mencionado servicio público está sujeta a una contraprestación, consistente en el pago de una cantidad de dinero proporcional al servicio recibido, cuando aquel no se cubre, dará lugar a que el prestador del mismo ejerza la facultad legal de suspenderlo, acto que, al ser consecuencia del incumplimiento, no exige que deba cumplirse con la garantía de legalidad a que se refiere el artículo 16 de la propia Constitución Federal, pues la suspensión del servicio no es un acto de autoridad que deba estar fundado y motivado, sino que resulta del ejercicio de una facultad que se ejerce cuando se surte el incumplimiento del contrato. En este proceder la administración pública los utiliza bajo dos esquemas distintos.

Primero, su situación en un contrato es idéntica al de los particulares, tal y como es definido en el Código Civil Federal mexicano y el Código de Comercio: compras (adquisición de un terreno de manera amistosa), ventas (de productos del dominio privado), alquiler (de un local para albergar a una asociación), prestación de servicios (para algunos colaboradores de la administración pública), seguros, suministro de energía eléctrica, etc. En todo caso, las reglas que regulan la emisión del consentimiento de la persona pública, son de derecho privado y se aplican al contrato, y que en caso de un contencioso, son el juez federal judicial u ordinario quien es competente.

Al respecto, la tesis aislada3 2a. XLII/2015 (10a.) de la Suprema Corte de la Justicia de la Nación (SCJN) del 19 de junio del 2015, corrobora este primer pro-

${ }^{3}$ Nota del autor: una tesis aislada en un criterio emitido por un Tribunal Colegiado o por la SCJN (en pleno o en salas) interpretando algún precepto legal, la tesis no es obligatoria, sin embargo, si sirve para 
ceder de la administración pública en México, en relación al suministro de energía eléctrica por un ente público.

La Segunda Sala de la Suprema Corte de Justicia de la Nación, en criterio mayoritario, determinó en la tesis aludida que los contratos de suministro de energía eléctrica son de naturaleza administrativa. Sin embargo, una nueva reflexión sobre el tema conduce a interrumpir dicho criterio, para determinar que de la interpretación de los artículos 1049 y 75, fracciones V y XXV, del Código de Comercio, se advierte que las cuestiones inherentes a los derechos y obligaciones derivados del suministro de energía eléctrica proporcionado por la Comisión Federal de Electricidad a los particulares, son de naturaleza comercial y, en consecuencia, las controversias suscitadas entre las partes derivadas de los derechos y obligaciones generados en el marco del contrato de suministro respectivo o con motivo de este, deben decidirse en la vía ordinaria mercantil, conforme al numeral 104, fracción II, de la Constitución Política de los Estados Unidos Mexicanos, que prevé la competencia de los tribunales de la Federación para conocer de todas las controversias del orden civil o mercantil sobre el cumplimiento y aplicación de leyes federales, así como que cuando solo se afecten intereses particulares, a elección del actor, podrán conocer de aquellas los jueces y tribunales del orden común. Tesis: Comisión Federal de Electricidad. Las controversias derivadas de los derechos y obligaciones generados en el marco del contrato de suministro de energía eléctrica son impugnables en la vía ordinaria mercantil (Época: décima época, registro: 2009410, instancia: segunda sala, tipo de tesis: aislada, fuente: semanario judicial de la federación, materia: Civil).

Pero también, la administración pública lleva a cabo actos que son de naturaleza contractual, porque descansan en el acuerdo de dos voluntades, sin embargo no son sometidos a las reglas que regulan los contratos ordinarios y por lo tanto, conciernen a la jurisdicción administrativa. En México, es el Tribunal Federal de Justicia Fiscal y Administrativa el órgano de disputas de derecho público, sin ser

orientar o unificar criterios jurídicos en el orden mexicano. De este modo, cuando la quejosa transcribe en su demanda de garantías o amparo una tesis aislada, implícitamente puede considerarse que pretende que el órgano jurisdiccional la aplique al caso concreto, por lo que este deberá verificar su existencia, y precisar si se acoge al referido criterio o externar las razones por las cuales se separa de él; lo anterior, independientemente de que la quejosa hubiere razonado o justificado su aplicabilidad al caso concreto. En consecuencia, la tesis no es un extracto, una síntesis o un resumen de una resolución (Rojas, 2007). 
una verdadera jurisdicción independiente, ya que se encuentra vinculada al sistema judicial u ordinario a través del amparo. Estos forman la categoría de los contratos administrativos.

En México la SCJN ha definido estos contratos mediante la tesis IX/2001, estableciendo que: la naturaleza administrativa de un contrato celebrado entre un órgano estatal y un particular puede válidamente deducirse de la finalidad de orden público que persigue, identificada también como utilidad pública o utilidad social, así como del régimen exorbitante del derecho civil a que está sujeto. Los Contratos Administrativos se distinguen por su finalidad de orden público y por el régimen exorbitante del derecho civil a que están sujetos (Época: novena época, registro: 189995, instancia: pleno, tipo de tesis: aislada, fuente: semanario judicial de la federación y su gaceta, tomo XIII, abril del 2001, materias: Administrativa, Civil, p. 324).

De ello se infiere, que en derecho mexicano, los contratos celebrados por un órgano estatal con los particulares están regidos por el derecho privado cuando su objeto no esté vinculado estrecha y necesariamente con el cumplimiento de las atribuciones públicas del Estado y, por lo mismo, la satisfacción de las necesidades colectivas no se perjudique, es decir, en aquellos actos en los que el Estado no haga uso de los medios que le autoriza su régimen especial. Por el contrario, cuando el objeto o la finalidad del contrato estén íntimamente vinculados al cumplimiento de las atribuciones estatales, de tal manera que la satisfacción de las necesidades colectivas no sea indiferente a la forma de ejecución de las obligaciones contractuales, entonces se estará en presencia de un contrato administrativo, siendo válido estipular cláusulas exorbitantes que, desde la óptica del derecho privado, pudieran resultar nulas, pero que en el campo administrativo no lo son, en atención a la necesidad de asegurar el funcionamiento regular y continuo del servicio público. Aunque la doctrina jurídica en México no ha llegado a un consenso respecto del concepto de servicio público, y poco se analizado dicho concepto, la SCJN lo ha tratado de definir mediante las siguientes notas características: 1 . El servicio público debe consistir en una actividad prestacional, es decir, una actividad que tiende a otorgar a otros una ventaja, un bien, un beneficio, etcétera, de cualquier naturaleza y, por lo tanto, varía el ingreso de quien la recibe o disminuye los gastos en que pudiera incurrir en el supuesto de no recibirlo.

La gran mayoría de las clausulas exorbitantes del derecho común están simplemente constituidas por clausulas inusuales, anormales con relación al plerumque fit (aquello que se produce con mayor frecuencia) de la vida privada. Gerges Vedel, 
Remarques sur la notion de clause exorbitante. En la mayoría de fallos de sistemas de dualidad de jurisdicción se define como una cláusula que inserta derechos u obligaciones externos por su naturaleza a los que son susceptibles de ser libremente consentidos por cualquiera en el marco de las leyes civiles y comerciales.

Dentro del marco del anterior razonamiento, la SCJN en tesis aislada VI.3o.A.50 A del 2001, hace una diferencia entre los dos tipos de contrato, estableciendo una incipiente, pero firme, dualidad de jurisdicción en el sistema jurídico mexicano, confirmando los lineamientos jurídicos para los contratos administrativos y los contratos privados de la administración:

Para determinar la naturaleza de un contrato administrativo frente a uno civil o mercantil, debe atenderse a ciertos factores. En los contratos privados, la voluntad de las partes es la ley suprema y su objeto los intereses particulares, mientras que en los administrativos está por encima el interés social y su objeto son los servicios públicos. En los privados, se da la igualdad de las partes, en los administrativos la desigualdad entre Estado y contratante. En los privados, las cláusulas son las que corresponden de manera natural al tipo de contrato, en los administrativos se dan las cláusulas exorbitantes. En los privados la jurisdicción para dirimir controversias recae en los tribunales ordinarios, en los administrativos interviene la jurisdicción especial, ya sean tribunales administrativos, si los hay, o en propia sede administrativa, según los trámites establecidos por la ley o lo estipulado en el contrato mismo. En resumen, para que se den los caracteres distintivos de un contrato administrativo deben concurrir los siguientes elementos: 1) el interés social y el servicio público; 2) la desigualdad de las partes, donde una necesariamente debe ser el Estado; 3) la existencia de cláusulas exorbitantes; y, 4) la jurisdicción especial (Época: novena época, registro: 188644, instancia: Tribunales Colegiados de Circuito, tipo de tesis: aislada, fuente: Semanario Judicial de la Federación y su Gaceta, tomo XIV, octubre del 2001, materia: Administrativa, p. 1.103).

Lo que permite encontrar una influencia directa del derecho francés, español y colombiano en el sistema jurídico mexicano, ya que iniciamos a circular por rumbos similares en esta materia. A diferencia de otros derechos, que han encuadrado el grueso de la contratación pública en las regulaciones comunes del derecho privado, encomendadas al juicio de los tribunales ordinarios, tal y como sucedía en México antes del año 2000, la solución francesa ha venido a partir en dos el sistema de 
contratos: una parte de los contratos de la administración pública se califica, en efecto, de privados y se les atribuye su conocimiento a la jurisdicción ordinaria; la otra en cambio, queda adscrita a la jurisdicción contencioso-administrativa, de donde va a concluirse que su regulación es objeto del Derecho Administrativo y no del Derecho Civil, los cuales son llamados contratos administrativos.

De lo anterior se desprende que existe una presunción a favor del derecho público cuando en un contrato, por su objeto o por las características esenciales de su régimen jurídico, está fuertemente marcado por la gestión pública, el juez administrativo deduce su competencia. Sin embargo, en el sistema jurídico mexicano sucede todo lo contrario, ya que ciertos contratos de la administración pública, como el suministro de electricidad, tienen un grado de indefinición como lo muestra la jurisprudencia 2a./J. 167/2011 (9a.), que viene a anular otras jurisprudencias que consideraba al contrato de suministro en comento como un contrato administrativo, y después de un análisis la misma SCJN proporciona un nuevo criterio jurisprudencial en México.

A diferencia de la noción de jurisprudencia en el sistema jurídico colombiano, la jurisprudencia en México surge de la práctica del juicio de garantías o amparo. La jurisprudencia se traduce en las interpretaciones y consideraciones jurídicas integrativas uniformes que hace una autoridad judicial designada para tal efecto por la ley, respecto de uno o varios puntos de derecho especiales y determinados que surgen de un cierto número de casos concretos semejantes que se presenten, en la inteligencia de que dichas consideraciones e interpretaciones son obligatorias para los inferiores jerárquicos de las mencionadas autoridades y que expresamente señala la ley. Además, la jurisprudencia constituye un medio de desentrañar el sentido de la ley, para el efecto de que los juzgadores puedan aplicar esta última en forma debida y con criterio uniforme, precisamente cuando pronuncien el fallo correspondiente (Burgoa, 1992, p. 821).

La jurisprudencia tiene facultades integradoras y va más allá de la norma, es decir, la verdadera jurisprudencia es aquella complementaria o integradora de las situaciones que no previó el legislador, adecuando la norma al caso concreto, toda vez que en muchas ocasiones las circunstancias de hecho están dando opciones distintas a lo establecido en un precepto legal. La Suprema Corte y los Tribunales, al fijar un criterio en una tesis jurisprudencial, estudia aquellos aspectos que el legislador no precisó, e integra a la norma los alcances que, no contemplados en esta, se producen en una determinada situación. 
Una nueva reflexión conduce a la Segunda Sala de la SCJN a abandonar los criterios contenidos en las jurisprudencias 2a./J. 98/2006 y 2a./J. 120/2006, así como en las tesis 2a. CXXX/2010 y 2a. CXXXI/2010, en los que se estableció que contra la determinación de ajuste en el monto del consumo de energía eléctrica efectuada por la Comisión Federal de Electricidad, derivada de la verificación al medidor del consumidor, las órdenes de verificación, cobro o corte del suministro de dicho fluido y su ejecución, y el aviso recibo por concepto de dicho suministro expedido por aquella, procede el recurso de revisión previsto en el artículo 83 de la Ley Federal de Procedimiento Administrativo, a través del cual pueden paralizarse sus efectos, y que contra la resolución recaída a dicho medio de defensa procede el juicio contencioso administrativo ante el Tribunal Federal de Justicia Fiscal y Administrativa. Igualmente hace posible la suspensión de los efectos de aquella; para ahora sostener que tales actos son inimpugnables mediante dichos medios de defensa, pues si bien tanto estos, como el juicio de amparo indirecto, son de distinta naturaleza y alcance, lo cierto es que comparten una nota fundamental consistente en que su procedencia versa en torno a la existencia de un acto de autoridad; naturaleza que no tienen los referidos actos, pues la relación jurídica entre los particulares usuarios del servicio de energía eléctrica y la Comisión Federal de Electricidad no corresponde a la de una autoridad y un gobernado (de supra a subordinación) sino, como ya lo definió esta Segunda Sala en las jurisprudencias 2a./J. 112/2010 y 2a./J. $113 / 2010$, en una relación de coordinación entre aquellos, originada mediante un acuerdo de voluntades donde ambas partes adquieren derechos y obligaciones recíprocos, la cual no puede desnaturalizarse en función de algún medio de defensa que el usuario haga valer contra los referidos actos dentro de esa relación, pues no corresponden a los privativos y de molestia previstos en los artículos 14 y 16 de la Constitución Política de los Estados Unidos Mexicanos, ya que no derivan de un mandamiento unilateral del Estado, sino de la mera consecuencia del contrato de suministro de energía eléctrica (Época: novena época, registro: 159944, instancia: segunda sala, tipo de tesis: jurisprudencia, fuente: Semanario Judicial de la Federación y su Gaceta, libro XIII, octubre del 2012, tomo 3, materia: Administrativa, tesis: 2a./J. 167/2011 (9a.), p. 1.457).

De esa manera, se infiere que debido a la reciente consolidación de un sistema exorbitante en la contratación pública, el sistema jurídico mexicano inicia su andar en el entendimiento los contratos administrativos desde la óptica del derecho público, y en consecuencia, se debe definir los aspectos de las prerrogativas del poder público. 


\section{b. Las prerrogativas del poder público}

Las prerrogativas del poder público, es un tema poco tratado, desde la doctrina o jurisprudencia mexicana. Dentro de la contratación, hemos estudiado que existen las cláusulas exorbitantes, que, según sus teorizadores originarios (Chevallier, 1979, p. 4), harían normalmente ilícito un contrato civil si se llegase a insertar en él. Sin embargo, subsiste al respecto confusión, que conviene despejar en el presente estudio.

La prerrogativa de poder público por excelencia con que la administración pública cuenta en sus contratos administrativos es, sin duda, el privilegio de la decisión unilateral y ejecutoria, previa al conocimiento judicial, que impone al contratista el deber de su cumplimiento inmediato con la carga de impugnación contencioso-administrativa si no está conforme con su legalidad; es aquí donde precisamente se inserta la práctica del recurso contencioso administrativo en su aplicación al contrato administrativo. En virtud de este privilegio, la administración pública puede decidir unilateralmente sobre: la perfección del contrato y su validez, la interpretación del contrato, la realización de las prestaciones debidas por el contratista (modo, tiempo, forma), la calificación de situaciones de incumplimiento, la imposición de sanciones contractuales en ese caso, la efectividad de estas, la prórroga del contrato, la concurrencia de motivos objetivos de extinción del contrato, la recepción y aceptación de las prestaciones contractuales, las eventuales responsabilidades del contratista durante el plazo de garantía, la liquidación del contrato, la apropiación o la devolución final de la fianza. Mediante tesis aislada los tribunales federales mexicanos constatan lo siguiente:

Todo contrato administrativo es un acuerdo de voluntades celebrado por la administración pública, con una finalidad de interés colectivo; y es precisamente esta última circunstancia la que justifica en ellos la existencia de cláusulas o prerrogativas exorbitantes al derecho común que colocan al particular contratante en una relación de subordinación frente a la propia administración. En este contexto, si con la finalidad de salvaguardar el interés de la comunidad, el Estado contratante conserva para sí y ante sí facultades legales suficientes para, entre otras cuestiones, dar por rescindida unilateralmente la relación contractual, esta acción ejecutiva que modifica o extingue derechos de los gobernados constituye, sin duda, un acto de autoridad susceptible de ser combatido a través del juicio de amparo (Tesis: I.7o.A.280 A, época: novena época, registro: 182024, instancia: Tribunales 
Colegiados de Circuito, tipo de tesis: aislada, tomo XIX, marzo del 2004, materia: Administrativa, p. 1.523).

Inversamente, el contratista no solo está vinculado por esas decisiones a reserva de un recurso posterior contra las mismas (recursos a interponer por las vías propias del derecho administrativo), sino que cuando pretenda que se produzca cualquiera de esos efectos, incluso cuando se trate de un incumplimiento de la administración pública, tiene la carga de solicitar de esta la resolución oportuna. Así, encontramos que el Tribunal Federal de Justicia Fiscal y Administrativa (Tribunal de lo Contencioso Administrativo Mexicano), dispone el artículo 14, fracción VII de su Ley Orgánica: Las que se dicten en materia administrativa sobre interpretación y cumplimiento de contratos de obras públicas, adquisiciones, arrendamientos y servicios celebrados por las dependencias y entidades de la Administración Pública Federal.

Este poder exorbitante no resulta propiamente del contrato mismo, sino de la posición jurídica general de la administración pública de su privilegio general de autotutela, de modo que es en sí mismo extracontractual. Son mecanismos derivados del poder de revisión que ejercen los órganos superiores sobre los inferiores y que consisten en la supervisión de la actuación de sus subordinados a fin de verificar su legalidad y oportunidad. Históricamente parece claro que la inserción de estos poderes en los contratos administrativos ha sido la consecuencia, y no la causa, de la atribución jurisdiccional de estos contratos a la vía contencioso administrativa, tal y como pasa en países que han seguido dicho sistema (Carbonero, 2010).

Sin embargo, la verdadera razón de fondo que justifica la aplicación de esta prerrogativa está en la relación inmediata del contrato con las necesidades públicas o con los "servicios públicos", cuya responsabilidad de gestión tiene atribuida la administración pública, y que debe atender con todas sus facultades específicas, sobre todo evitando retrasos, que serían ineludibles si la Administración tuviera que demandar ejecutorias judiciales o si su actuación pudiese ser paralizada por el simple expediente de un proceso. En el mismo sentido, los tribunales mexicanos han razonado: SCJN en tesis aislada VI.3o.A.50 A del 2001, [...] en los contratos privados, la voluntad de las partes es la ley suprema y su objeto los intereses particulares, mientras que en los administrativos está por encima el interés social y su objeto son los servicios públicos.

Por lo tanto, la administración cuenta con un medio formal determinado de ejercitar sus derechos en el contrato que excede de las facultades propias de los 
sujetos privados, el medio de la decisión ejecutoria y que paralelamente genera como consecuencia que el contratista particular se ve privado de otros medios que para el ejercicio de sus propios derechos le reconocería el derecho civil, por ejemplo: el utilizar su condición de poseedor para desplazar a la otra parte la carga de accionar, el acudir directamente al juez en cualquier momento, el no tener que someter sus pretensiones a una verificación previa del otro contratante, el carecer de la carga de impugnar, bajo sanción de firmeza definitiva e irrecurrible las decisiones de este otro contratante. Por otra parte, deja absolutamente intactas las reglas de fondo que definen los contenidos obligacionales del contrato. Si la administración pública decide en contra de tales reglas de fondo (por ejemplo, si acuerda calificar de incumplimiento lo que no lo es, o pretende que se han producido situaciones de resolución que no están legalmente justificadas, o se apropia de la fianza sin razón obligacional que lo justifique, etc.), sus decisiones serán anuladas en México por el tribunal contencioso administrativo, puesto que esas decisiones solo tienen un valor previo e inmediato (ejecutoriedad), pero no un valor definitivo (firmeza), que solo la sentencia contencioso administrativa podrá declarar. Así, la tesis aislada VI.3o.A.4 A (10a.) de los tribunales federales mexicanos establece:

Se obtiene que la rescisión administrativa de un contrato de obra pública, decretada por las dependencias y entidades de la Administración Pública Federal, reúne las características para ser considerada como un acto de autoridad, pues con fundamento en los artículos 134 de la Constitución Política de los Estados Unidos Mexicanos y 61 de la Ley de Obras Públicas y Servicios Relacionados con las Mismas, se emite esa decisión unilateral, extinguiendo por sí o ante sí una relación contractual en la que es parte un particular, afectando su esfera jurídica; asimismo, dicha rescisión la decreta un órgano integrante de la estructura orgánica de la entidad contratante, sin acudir a los tribunales judiciales o administrativos y sin el consenso de la voluntad del afectado. Dicho acto pude ser impugnado en las vías legales correspondientes. (Época: décima época, registro: 2003747, instancia: Tribunales Colegiados de Circuito, libro XX, mayo del 2013, tomo 3, materia: Común, p. 2.103).

En el sistema mexicano se confirma mediante tesis aislada: 
De conformidad con el artículo 52, fracción V, inciso d), de la Ley Federal de Procedimiento Contencioso Administrativo las Salas del Tribunal Federal de Justicia Fiscal y Administrativa están facultadas para declarar la nulidad de la resolución impugnada, determinar el derecho subjetivo y condenar al pago de daños y perjuicios ocasionados por los servidores públicos; en esas condiciones, cuando se impugna una resolución en la que se declaró la legalidad de una diversa inconformidad presentada contra un acto dictado dentro de un procedimiento de licitación, aun cuando ya hubiese concluido, no se actualiza el supuesto previsto en la fracción $V$ del artículo 9o. de la citada ley, sino que resulta procedente el juicio de nulidad pues, si bien no puede dejarse sin efecto la resolución con que culmina la licitación, ello no impide que el órgano jurisdiccional pueda analizar la ilegalidad del acto impugnado para determinar si dicho actuar ocasionó algún daño o perjuicio al particular actor y, de ser así, condene al pago de una indemnización por los causados; en razón de ello, no puede considerarse que el juicio haya quedado sin materia, máxime que de conformidad con el artículo 40 de la Ley Federal de Procedimiento Contencioso Administrativo, las salas del referido tribunal están obligadas a verificar la existencia del derecho subjetivo que reclama la actora (Semanario Judicial de la Federación y su Gaceta, tomo XXXIII, mayo del 2011, materia: Administrativa, tesis: I.17o.A.31 A, p. 1.204).

En la práctica, el contrato administrativo y el contrato privado conviven sin problema alguno, es decir, cualquier contrato es capaz de reflejar elementos del uno y del otro, sin que por ello varié la esencia de la institución de la contratación. Lo que puede ocurrir es que en ciertos contratos directamente vinculadores a la actividad atípica del órgano administrativo, por ejemplo, obras y servicios públicos los elementos jurídicos administrativos son más intensos que en otros. A estos contratos en el derecho mexicano se les llama contratos administrativos y su conocimiento se atribuye a la jurisdicción contencioso administrativa. De esa manera y después de demostrar el incipiente derecho exorbitante de la administración pública y sus prerrogativas de poder público en México, a continuación analizaremos el procedimiento de celebración de contratos.

\section{Aspectos generales de la contratación pública en México}

El artículo 134 de la Constitución Política de los Estados Unidos Mexicanos establece que todas las contrataciones en las que el Estado sea parte deberán sujetarse 
a procedimientos de licitación. La licitación se define como un procedimiento "por el cual el poder adjudicador selecciona la oferta económica más ventajosa, sin negociación, sobre la base de criterios objetivos previamente llevados al conocimiento de los candidatos" (artículo 33, Code des marchés publics - Francia). A fin de asegurar, al interés estatal, las mejores condiciones disponibles en cuanto a precio, calidad, financiamiento, oportunidad y demás circunstancias pertinentes y que, por excepción, cuando no sea idónea la licitación, las leyes reglamentarias deberán establecer las bases, procedimientos, reglas, requisitos y demás elementos que sirvan para acreditar la economía, eficiencia, eficacia, imparcialidad y honradez, que aseguren las mejores condiciones de contratación para el Estado.

\section{a. Marco jurídico}

El artículo 134 de la Constitución Federal, no solo tiene aplicación en el ámbito federal, sino también en los Estados, pues establece los principios que deben observarse en las adquisiciones, arrendamientos y enajenaciones de todo tipo de bienes, prestación de servicios de cualquier naturaleza y la contratación de obra, a favor de la Federación, los Estados, los Municipios, el Distrito Federal y los órganos político-administrativos de sus demarcaciones territoriales. A pesar de lo anterior y para efectos del presente estudio, únicamente estudiaremos la legislación federal, que comprende esencialmente las siguientes leyes en materia de contratación pública: La Ley de Adquisiciones, Arrendamientos y Servicios del Sector Público (LAASSP); La Ley de Obras Públicas y Servicios Relacionados con las Mismas (LOPSRM); Sus respectivos Reglamentos (RLAASSP y RLOPSRM) y la Ley Federal Anticorrupción en Contrataciones Públicas (LFACP).

Asimismo, existen otras 22 Leyes que reglamentan paralelamente alguna materia de las contrataciones públicas, tales como la Ley Federal de Presupuesto y Responsabilidad Hacendaria, la Ley de Ingresos, Ley Federal de Transparencia y Acceso a la Información Pública Gubernamental; la Ley Federal sobre Metrología y Normalización; la Ley Federal de Competencia Económica; la Ley de Coordinación Fiscal, entre otras. Podemos observar que la normatividad en Colombia también es vasta: Ley 80 (año 1993) que expide el Estatuto General de Contratación de la Administración Pública; Ley 1150 (año 2007) que complementa la eficiencia y transparencia en la Ley 80 y otras disposiciones generales sobre contratación con recursos públicos; Ley 527 (año 1999) que reglamenta el acceso y uso de los mensajes 
de datos, el comercio electrónico y las firmas digitales; y establece las entidades de certificación; Ley 816 (año 2003) que fomenta el apoyo a la industria nacional a través de la contratación pública; Ley 1474 (año 2011) que dictan normas orientadas a fortalecer los mecanismos de prevención, investigación y sanción de actos de corrupción, así como la efectividad del control de la gestión pública; Decreto de Ley 4170 (año 2011) mediante el cual se crea la Agencia Nacional de Contratación Pública -Colombia Compra Eficiente- y determina sus objetivos y estructura.

Para la Federación o gobierno nacional, el monto mínimo para llevar a cabo cualquier procedimiento de contratación pública al amparo de las leyes reglamentarias es de 300 veces el SMDGVDF (Salario Mínimo Diario General Vigente en el Distrito Federal) equivalente aproximadamente $\$ 21,030$ pesos (1.402 dólares), dato calculado con base al salario mínimo del “área geográfica $A$ ” de $\$ 70.10$ pesos, vigente desde el 1 de abril del 2015, es decir, que todas las compras que se realicen por debajo de este umbral se podrán llevar a cabo con fondo revolvente o caja chica (importe que las dependencias y entidades de la Administración Pública Federal destinan para cubrir sus necesidades de compra sin llevar a cabo un procedimiento de contratación, cuyo monto es definido y autorizado por la Secretaría de Hacienda y Crédito Público). A diferencia de Colombia, donde el monto mínimo para efectuar un procedimiento de contratación depende del Presupuesto Anual de cada dependencia y del tipo de contratación; y en unos casos se define en dólares americanos, así como en Derechos Especiales de Giro, además de los umbrales (menor cuantía) establecidos para cada acuerdo.

La normatividad nacional obliga a las dependencias y entidades a formular sus programas anuales de adquisiciones y de obra pública; así como a publicitarlos a través del Diario Oficial de la Federación 4 y a través de la Secretaria de la Función Pública5, a diferencia de Colombia, donde existe la Agencia Nacional de Contratación Pública "Colombia Compra Eficiente", como una entidad descentralizada de la Rama Ejecutiva de orden nacional, con personalidad jurídica, patrimonio propio y autonomía administrativa y financiera, adscrita al Departamento Nacional de Planeación. En México las compras federales siguen siendo centralizadas. la cual difunde la información correspondiente a las licitaciones públicas en el sistema Electrónico de Compras Gubernamentales denominado CompraNet, y de sus

\footnotetext{
${ }^{4}$ Nota del autor: las convocatorias se deben publicar en el diario oficial de la federación; Actualmente todos los martes y los jueves del año (con excepción de días festivos oficiales).

${ }_{5} \mathrm{Al}$ respecto ver: http://www.colombiacompra.gov.co/colombia-compra
} 
páginas de internet el último día del mes de enero de cada año. El sistema electrónico de información pública gubernamental sobre adquisiciones, arrendamientos y servicios, integrado entre otra información, por los programas anuales en la materia, de las dependencias y entidades; el registro único de proveedores; el padrón de testigos sociales; el registro de proveedores sancionados; las convocatorias a la licitación y sus modificaciones; las invitaciones a cuando menos tres personas; las actas de las juntas de aclaraciones, del acto de presentación y apertura de proposiciones y de fallo; los testimonios de los testigos sociales; los datos de los contratos y los convenios modificatorios; las adjudicaciones directas; las resoluciones de la instancia de inconformidad que hayan causado estado, y las notificaciones y avisos correspondientes. Dicho sistema será de consulta gratuita y constituirá un medio por el cual se desarrollarán procedimientos de contratación. El sistema estará a cargo de la Secretaría de la Función Pública, a través de la unidad administrativa que se determine en su reglamento, la que establecerá los controles necesarios para garantizar la inalterabilidad y conservación de la información que contenga.

Las proposiciones que reciben con motivo de la oferta de bienes y servicios que licita el Estado, deben ser evaluadas y analizadas. Como se puntualiza en la LAASSP y LOPSRM, una vez hecha la evaluación de proposiciones el contrato se adjudicará al licitante cuya oferta resulte solvente, porque cumple con los requisitos legales, técnicos y económicos establecidos en la convocatoria a la licitación y por tanto, garantiza el cumplimiento de las obligaciones respectivas. Posteriormente la convocante emitirá un fallo que incluirá, entre otras cosas, el nombre del o los licitantes a quienes se adjudique el contrato, indicando las razones que motivaron la adjudicación, además de la fecha, lugar y hora para la firma del contrato, la presentación de garantías y en su caso, la entrega de anticipos.

Los proveedores que celebren los contratos deberán garantizar los anticipos, así como el cumplimiento del contrato. La garantía de cumplimiento deberá presentarse en el plazo o fecha prevista en la convocatoria de la licitación; o en su defecto, dentro de los diez días naturales siguientes a la firma del contrato, salvo que los bienes o servicios se entreguen durante el citado plazo; y la garantía correspondiente al anticipo se presentará previamente a la entrega del mismo, en la fecha establecida en el contrato.

El carácter de los procedimientos de contratación que permite la legislación puede ser: 
- Nacional, en donde únicamente participan personas de nacionalidad mexicana y los bienes a adquirir son producidos en el país, y cuentan por lo menos con un $50 \%$ de contenido nacional, o bien, por encontrarse debajo de los umbrales establecidos en los tratados, o cuando se haya realizado la reserva correspondiente al haberlos rebasado.

- Internacional bajo la cobertura de tratados, cuando resulta obligatorio conforme a los tratados, en donde solo participan licitantes mexicanos y extranjeros de países con los que México tiene celebrado un tratado de libre comercio con capítulo de compras gubernamentales' en el caso particular de Colombia, ya que los proveedores colombianos pueden participar en términos preferenciales. El tratado de libre comercio tiene un capítulo de Contratación Pública que ofrece garantías y beneficios a los proveedores colombianos cuando participen en las contrataciones públicas mexicanas.

- Internacionales abiertas, en las que participan licitantes mexicanos o extranjeros, cualquiera que sea el origen de los bienes, servicios u obras a contratar. En ese sentido, la SCJN se ha pronunciado de la siguiente manera: [...] el legislador ordinario reglamentó los principios en la Ley de Adquisiciones, Arrendamientos y Servicios del Sector Público, que en su artículo 28 señala que podrán efectuarse licitaciones nacionales e internacionales; las primeras cuando solo puedan participar personas de nacionalidad mexicana y los bienes a que se refieran sean producidos en el país y cuenten por lo menos con un $50 \%$ de contenido nacional, mientras que en las segundas pueden participar personas mexicanas o extranjeras y los bienes a adquirir sean de origen nacional o extranjero. Por tanto, el último párrafo del referido precepto al establecer que en las licitaciones internacionales podrá negarse la participación de extranjeros cuando con el país del cual sean nacionales no se tenga celebrado un tratado y aquel no conceda un trato recíproco a los licitantes, proveedores, bienes o servicios mexicanos, no transgrede los postulados contenidos en el artículo 134 de la Constitución Política de los Estados Unidos Mexicanos, pues al otorgarse a la dependencia o entidad licitante la facultad discrecional de determinar si en las licitaciones públicas internacionales convocadas se autorizará o no la participación a los extranjeros, $[\ldots]$ en la medida que estarán en posibilidad de ponderar en cada caso la conveniencia de permitir o negar la participación de extranjeros respecto de los que no exista obligación derivada de tratados internacionales o trato 
de reciprocidad internacional, cuando así convenga al interés y beneficio de la colectividad y al desarrollo de la economía nacional, pues corresponde al propio Estado la rectoría del desarrollo nacional, así como la planeación, conducción, coordinación y orientación de aquella, conforme a los artículos 25 y 26 de la Constitución Federal (Época: novena época, registro: 179273, instancia: segunda sala, tipo de tesis: aislada, fuente: Semanario Judicial de la Federación y su Gaceta, tomo XXI, febrero del 2005, materias: Constitucional, Administrativa, tesis: 2a. XXI/2005, p. 347).

Hoy en día, la legislación mexicana en contrataciones públicas (LAASSP y LOPSRM) contempla mecanismos para la solución de controversias, recursos de inconformidad, conciliaciones y sanciones expeditas. El plazo del proceso para resolver inconformidades se ha reducido de 144 a 51 días en promedio, también se cuenta como mecanismo de solución de controversias al arbitraje, se ha establecido la conciliación de precios en contratos de emergencia, la factibilidad de solicitar al licitante aclaraciones o información adicional sobre sus propuestas y el peritaje. Por su parte, en el 2012 se publicó en el Diario Oficial de la Federación (DOF) la Ley Federal Anticorrupción en Contrataciones Públicas (LFACP), la cual considera varias medidas anticorrupción en materia de contrataciones públicas para castigar actividades colusorias, de soborno, simulación de eventos, extorsión, tráfico de influencias y excluir la participación de empresas que realizan prácticas monopólicas. Aún falta por consolidar algunos aspectos del marco jurídico, en particular el tema de las sanciones e inhabilitación de funcionarios públicos por medio de un derecho disciplinario y fiscal mucho más punitivo. Analizado lo anterior, estudiaremos a continuación las modalidades de contratación en el sistema jurídico mexicano.

\section{b. Modalidades de contratación}

En México, la contratación pública tiene una complejidad técnica, ya que reviste de principios generales que la administración debe cumplir en su procedimiento de contratación. De la misma manera, la ley establece las bases del procedimiento de contratación y se contempla el uso de la tecnología para hacer eficiente el procedimiento de contratación. 


\section{Principios generales}

Desde esta perspectiva que otorga el marco jurídico, la licitación pública consiste en un llamado que la administración pública hace a los particulares de forma impersonal para que le formulen ofertas a fin de llevar a cabo una contratación, lo que, de acuerdo con la doctrina6, tiene dos consecuencias: a) quien se presenta y formula una oferta debe ajustarse estrictamente a las condiciones fijadas en el llamado, quedando obligado a mantenerlas durante el plazo que en este se establezca; y, b) la administración puede aceptar o rechazar las ofertas que se le hagan, sin responsabilidad alguna, siempre y cuando respete la legalidad del procedimiento. Así, aquel llamado implica un conjunto de actos que conforman un procedimiento preparatorio de la actividad contractual del Estado, por lo que la naturaleza jurídica de la licitación pública es la de un procedimiento administrativo integrado por una diversidad de actos administrativos y simples actos de la administración, como formas jurídicas preparatorias de su actividad contractual, de manera que su omisión invalida los contratos produciendo su nulidad absoluta o de pleno derecho, la que pueden invocar la propia administración, el particular contratante y los terceros interesados.

El procedimiento administrativo de licitación pública, en su desarrollo cronológico, constituye una concatenación de actos desplegados en las siguientes etapas: I. El pliego de condiciones conforme al cual se hace el llamado a los interesados (esto mediante el Diario Oficial de la Federación o el sistema CompraNet); II. La presentación de ofertas; y, III. El estudio de estas por la administración, que culmina con la aceptación de la más conveniente en cuanto a precio, calidad, financiamiento, oportunidad y demás circunstancias pertinentes (conforme al artículo 134 de la Constitución Política de los Estados Unidos Mexicanos) a través de un fallo y su notificación al interesado. En esta última etapa debe establecerse cuáles son los derechos de los participantes en la licitación que no resultaron ganadores, si es que les asiste alguno, pues aunque no tienen derecho a la adjudicación, sí lo tienen a la participación en una competencia justa. En este sentido, conviene precisar que en caso de existir actos que vicien el procedimiento de licitación, los participantes

\footnotetext{
${ }^{6}$ En particular ver: Ibrahim Elbeherry, Théorie des contrats administratifs et marchés publics internationaux, tesis, Humanities and Social Sciences. Université Nice Sophia Antipolis, 2004; J. F. Prevost, A la recherche du critère du contrat administratif (la qualité des cocontractants), RDP, 1971, p. 817; Y. Brard, Le mandat comme fondement des contrats administratifs entre personnes privées, JCP, 1981, 1, p. 3.031.
} 
cuentan con medios de impugnación para la defensa de su interés legítimo, el que debe entenderse como la facultad para lograr que la actuación administrativa se adecúe a la ley, aunque no derive en un beneficio para ellos. Dentro del marco jurídico colombiano en cuanto a las inconformidades y controversias, las personas inconformes con la calificación y clasificación de las bases podrá impugnarlas ante la Cámara de Comercio, el cual podrá ser objeto de recursos de reposición, de la nulidad y del restablecimiento, en términos del código Contencioso Administrativo.

Además, el procedimiento administrativo de licitación en México se rige por los siguientes principios esenciales, los cuales se han confirmado los Tribunales Federales (Tesis aislada: tesis: I.4o.A.587 A, julio del 2007, p. 2.652): 1) concurrencia, que asegura a la administración pública la participación de un mayor número de ofertas, lo cual permite tener posibilidades más amplias de selección y obtención de mejores condiciones en cuanto a precio, calidad, financiamiento y oportunidad, entre otras; 2) igualdad, que es la posición que guardan los oferentes frente a la administración, así como la posición de cada uno de ellos frente a los demás; 3) publicidad, que implica la posibilidad de que los interesados conozcan todo lo relativo a la licitación correspondiente, desde el llamado a formular ofertas hasta sus etapas conclusivas, en Colombia la entidad contratante es responsable de garantizar la publicidad de todos los procedimientos y actos asociados a los procesos de contratación a través del SECOP y de su página web, salvo los asuntos expresamente sometidos a reserva. En México se lleva a cabo a través del DOF y del sistema CompraNet; y 4) oposición o contradicción, que deriva del principio de debido proceso que implica la intervención de los interesados en las discusiones de controversia de intereses de dos o más particulares, facultándolos para impugnar las propuestas de los demás y, a su vez, para defender la propia. El propio sistema jurídico ha ido acotando estos principios, para evitar la discrecionalidad en el procedimiento de adjudicación. Ahora, procedemos a analizar el procedimiento de contracción pública.

\section{Procedimiento de contratación}

Los procedimientos de contratación en México son:

1. Licitación pública: concurso que mediante convocatoria pública, acepta la libre presentación de proposiciones solventes a fin de asegurar al Estado las mejores condiciones de compra disponibles. 
2. Invitación al menos a tres personas (ITP): procedimiento restringido en el que únicamente participan las empresas que son invitadas.

3. Adjudicación directa $(A P)$ : contratación que no requiere llevar a cabo un procedimiento específico, sin embargo, este debe tener un seguimiento puntual.

A diferencia de Colombia, la administración pública en México se encuentra limitada en los procedimientos de contratación, que además de la Licitación Pública y la Contratación Directa, en Colombia se contempla la Selección Abreviada y el Concurso de Méritos (ver Decreto 734, 13 de abril del 2012).

Las dependencias y entidades en México pueden optar por llevar a cabo una excepción a la licitación pública y realizar bajo su responsabilidad una invitación con mínimo tres personas (ITP) o una adjudicación directa (AD), siempre que la suma de estas contrataciones no exceda del $30 \%$ del presupuesto total asignado y cuando el importe de cada operación no exceda los montos máximos que se establecen en el Presupuesto de Egresos de la Federación para adquisiciones y obras (se contempla en LAASSP Titulo Segundo, capítulo tercero, artículos 40 y 42; LOPSRM título segundo, capítulo tercero, artículos 41 y 43).

Ahora bien, las ITP y AD también pueden llevarse a cabo siempre que se justifique alguna de las causas de la LAASSP en su artículo 41 y la LOPSRM artículo 42. Asimismo, en relación a la adjudicación directa los Tribunales Federales se han pronunciado sobre las exigencias de la misma:

[...] Que el contrato solo pueda celebrarse con una determinada persona, porque posee la titularidad o el licenciamiento exclusivo de patentes, derechos de autor $\mathrm{u}$ otros derechos exclusivos; que la contratación se realice con fines exclusivamente militares o para la armada, o existan razones justificadas para la adquisición o arrendamiento de bienes de marca determinada; además, en términos del referido artículo 42, el comentado procedimiento es posible cuando el importe de cada operación no exceda los montos máximos que se establezcan en el Presupuesto de Egresos de la Federación, siempre que las operaciones no se fraccionen para quedar comprendidas en los supuestos de excepción a la licitación pública [...].

Consecuentemente, para que una dependencia o entidad pueda optar por no llevar a cabo el procedimiento de licitación pública y, en su lugar, celebrar contratos 
a través de adjudicación directa, es necesario y obligatorio que se actualicen conjuntamente tres hipótesis, a saber: a) que se trate de cualquiera de los supuestos establecidos en las diecinueve fracciones a que alude el mencionado artículo 41 de la LAASSP; b) que el importe de las operaciones a realizar no exceda los montos máximos que al efecto se establecen en el Presupuesto de Egresos de la Federación, siempre y cuando dichas operaciones no se fraccionen para quedar comprendidas en los supuestos de excepción a la licitación pública; y, c) una vez actualizados los dos supuestos anteriores, la selección de tal procedimiento deberá fundarse y motivarse, según las circunstancias que concurran en cada caso, en criterios de economía, eficacia, eficiencia, imparcialidad y honradez que aseguren las mejores condiciones para el Estado, además de que, el acreditamiento del criterio en el que se funde, así como la justificación de las razones para el ejercicio de la opción, deberán constar por escrito y firmarse por el titular del área usuaria o requirente de los bienes o servicios (Época: décima época, registro: 2002951, instancia: Tribunales Colegiados de Circuito, tipo de tesis: aislada, fuente: Semanario Judicial de la Federación y su Gaceta, libro XVIII, marzo del 2013, tomo 3, materia: Administrativa, tesis: I.9o.A.23 A (10a.), p. 1.903).

También, la adjudicación directa aplica al no existir bienes o servicios alternativos o sustitutos técnicamente razonables, o se trate de una persona que posee la titularidad o el licenciamiento exclusivo de patentes, derechos de autor u otros derechos exclusivos. En este contexto, para efectos de la adjudicación directa de un contrato celebrado en los términos señalados, es necesario que el particular acredite fehacientemente ante la autoridad correspondiente que posee la titularidad o licencia exclusiva de patentes, derechos de autor u otros derechos exclusivos, mediante la comprobación de su registro ante el Instituto Mexicano de la Propiedad Industrial (Época: novena época, registro: 164182, instancia: Tribunales Colegiados de Circuito, tipo de tesis: aislada, fuente: Semanario Judicial de la Federación y su Gaceta, tomo XXXII, agosto del 2010, materia: Administrativa, tesis: I.4o.A.714 A, p. 2.201). Así, el factor publicidad y rol del uso de los medios electrónicos es muy importante dentro del procedimiento de contratación, el cual será analizado a continuación.

\section{El uso de medios electrónicos}

CompraNet es el sistema electrónico de información pública gubernamental sobre adquisiciones, arrendamientos, servicios, obras públicas y servicios relacionados 
con las mismas de uso obligatorio para el registro electrónico de las operaciones de contratación pública que lleva a cabo la Administración Pública Federal.

Este sistema contribuye y trata de fomentar la generación de una política general en materia de contrataciones públicas, con la finalidad de generar transparencia, el seguimiento de las adquisiciones, arrendamientos de servicios y obras del sector público, así como concebir la información necesaria que permita la adecuada planeación, programación y presupuesto, además de la evaluación integral de las contrataciones públicas. CompraNet inició operaciones en el año 1997, siendo en ese entonces un instrumento para divulgar información relativa a las convocatorias y las bases de licitación de los procedimientos de compras del sector público. En ese sentido, en Colombia, todas las regiones, departamentos, provincias, la capital, distritos especiales, áreas metropolitanas, asociaciones, $\mathrm{mu}-$ nicipios, establecimientos públicos, empresas industriales y comerciales del Estado que tengan participación superior al $50 \%$, así como entidades descentralizadas indirectas y toda personalidad jurídica utilizará el Sistema Electrónico para la Contratación Pública (SECOP) y debe apegarse a la normativa nacional existente en esta materia. En México, de acuerdo con la información que administra CompraNet, se tienen registrados en el sistema más de 350 dependencias y entidades, Estados y municipios del país, los cuales realizan procesos de contratación a través de 3.329 Unidades Compradoras.

En el año 2000 CompraNet se transformó al concentrar la posibilidad de recibir proposiciones de manera electrónica, sin embargo, el registro o acreditación de unidades compradoras y potenciales licitantes constituía un costo transaccional significativo al requerir presencia física para ello.

Hasta el 2009 fueron registradas 11 mil empresas con posibilidad de tramitar proposiciones de manera electrónica. Derivado de los cambios en el uso de medios electrónicos, así como la necesidad de trasladar a una herramienta que hiciera más eficientes y transparentes los procesos de compras del sector público, la búsqueda para incorporar mejores prácticas, que además fueran consistentes con las reformas a la legislación, se inició la configuración del nuevo CompraNet, misma que entró en operación a partir del 28 de junio del 2010. La transición a la nueva plataforma CompraNet duró un año, periodo durante el cual, las dependencias y entidades se encargaron de obtener su certificación para operar la versión actualizada, de este modo, el 28 de junio del 2011 se publicó en el DOF el “Acuerdo por el que se establecen las disposiciones que se deberán observar para la utilización del Sistema 
Electrónico de Información Pública Gubernamental denominado CompraNet", fecha a partir de la cual, todos procedimiento mayor a 300 días de SMDGVDF (aproximadamente 20 mil pesos), se realizan a través de la nueva versión de CompraNet. También la plataforma de contrataciones públicas de Colombia presento la actualización de su página web de contrataciones públicas "Colombia Compra Eficiente", con nuevos módulos, a principios de 2013, entre los que destacan: Formular planes, políticas y programas para optimizar la oferta y demanda en el mercado.

- Implementar la normativa necesaria para mejor la eficiencia de las operaciones.

- Desarrollar y difundir las políticas, normas e instrumentos para facilitar las compras y promover la eficiencia.

- Coordinar para el cumplimiento de sus objetivos con otras entidades públicas.

- Elaborar estudios, diagnósticos y estadísticas para mejorar la efectividad del Sistema, etc.

Es pertinente anotar que las transacciones en CompraNet permiten, entre otros factores, la publicación del proyecto de convocatoria, de juntas de aclaraciones, de la apertura electrónica de proposiciones, del fallo, de datos relevantes de contratos, de convenios modificatorios, de solicitudes de información a licitantes, así como el procedimiento de contratación. En contraparte, el SECOP contempla el mecanismo de subasta inversa para el suministro de bienes y servicios de características técnicas uniformes que comparten patrones de desempeño y calidad objetivamente definidos, todo mediante previo Acuerdo Marco de precios o procedimientos de adquisición de bolsa de productos o catálogo. La subasta puede adelantarse de manera electrónica o presencial. Para el efecto, el sistema CompraNet permite con facilidad a cualquier usuario conocer algunos aspectos de la publicación, sin necesidad de estar registrado en el sistema.

\section{Conclusiones}

Desde hace 6 años se inició un proceso de simplificación en la contratación pública en México en el que se otorgó un lineamiento para una reestructura tanto legal como organizacional, y se ha trabajado en el fortalecimiento de los cambios que en su origen dieron el ejemplo para transformar de manera integral la perspectiva 
de los compradores públicos y llegar a obtener una mejora sustancial del diseño y operación institucional, mayor certeza jurídica, procedimientos homólogos, simplificaciones administrativas disminución de los plazos en la ejecución de los procesos, ahorros económicos derivados del uso de las estrategia de contratación, sistematización de procesos 100 \% electrónicos, rendición de cuentas, reducción en los tiempos de respuesta ante la interposición de inconformidades, un padrón de identificación de proveedores, generación de indicadores de gestión, inhibición de prácticas corruptas, entre otros.

De conformidad con lo dispuesto anteriormente, es importante mencionar que el sistema electrónico de información pública gubernamental, CompraNet, obtuvo el premio a lo Mejor del e-business en México (2012), en la categoría Gobierno otorgado por CNN Expansión, el motivo del premio se debe a que CompraNet se transformó en un sistema 100 \% transaccional que promueve la transparencia a través de la información pública gubernamental de la cual se tiene registro.

Pese a estos esfuerzos, la actual regulación jurídica de los contratos administrativos se encuentra lejos de ser la herramienta jurídica perfecta para la asignación de bienes y servicios a los particulares, ya que no existe un marco jurídico adecuado para luchar en contra de la corrupción; entre otras razones por la excesiva discrecionalidad por parte de las autoridades y por los procesos turbios de adjudicación. Sin duda alguna, el sistema de contratación pública sigue afianzando sus cimientos, sin embargo no estará completo sin un efectivo marco jurídico integral de derecho disciplinario y de derecho fiscal, que ponga candado a esas prácticas desleales y sancione severamente la corrupción.

\section{Referencias}

Alessia, A. (2015). Solución de controversias $4 G$ o la oscura bola de cristal. Disponible en http:// www.larepublica.co/soluci\%C3\%B3n-de-controversias -4g-o-la-oscura-bola-de- cristal_249761

Burgoa, I. (1992). Juicio de Amparo. México: Porrúa.

Chevallier, J. (1979). Les fondements idéologiques du droit administratif français. PUF.

Fernández, J. y Herrera, J. A. (2004). Teoría y praxis de la contratación administrativa. México: UNAM, IIJ. 
Fernández, J. y Sánchez, J. S. (Coordinadores). (2007). Contratos administrativos, Culturas y Sistemas Jurídicos Comparados. México: UNAM, IIJ.

Fernández, J. (2011). Los vicios de la contratación pública en México, Derecho UPC. En Revista de la Facultad de derecho de la Pontificia Universidad Católica de Perú, 66, 476.

Gallardo, J. (2010). La adjudicación de los contratos administrativos, Origen, Evolución y Sistema Actual. Universidad de Granada.

García de Enterría, E. (2001). Curso de Derecho Administrativo I. Madrid: Civitas.

Morand-Deviller, J. (2010). Curso de Derecho Administrativo. Bogotá: Universidad del Externado.

Rivero, J. y Waline, J. (2010). Droit Administratif. Paris: Dalloz. 